\title{
Interactive comment on "Motion of dust particles in dry snow under temperature gradient metamorphism" by Pascal Hagenmuller et al.
}

\author{
Kevin Hammonds (Referee) \\ kevin.hammonds@montana.edu \\ Received and published: 17 April 2019
}

In this paper, the authors provide both quantitative and qualitative evidence in support of their findings, that dust particles in dry snow can migrate within a snowpack when placed under an imposed temperature gradient. These experiments were conducted from within a controlled laboratory setting, such that the imposed temperature gradient could be finely controlled $(18 \mathrm{~K} / \mathrm{m})$, and also compared to a parallel experiment conducted under near-isothermal $(<5 \mathrm{~K} / \mathrm{m})$ conditions. The light absorbing particles (LAP's) were tracked with X-ray computed microtomography (micro-CT) in both experiments, and a migration rate was quantified, based on the imposed temperature gradient and center of mass of the LAP's. Three modes of migration were also identified. The authors then went on to demonstrate the impact of the spatial location of 
the LAP's as a function of snow depth on the snow radiative properties. As cited by the authors, this work is of relevance to those studying 1) the microstructural evolution of a snowpack under natural conditions, 2) the effects of LAP's on the radiative energy balance and albedo of natural snowpacks, and 3) the optical properties of a snowpack under natural conditions.

Overall, this is a very well-written and organized paper, and in my opinion, due to the novelty of these experiments, the detail by which the authors analyzed their data in support of their findings, and the broader impacts on the cryospheric research community, I recommend this study for immediate publication in The Cryosphere, pending only minor technical/content revisions.

\section{Recommendation: Publication with Minor Revisions}

\section{General Comments/Questions:}

1) Because these experiments are worthy of being repeated and extended to other problems related to snow metamorphism and its radiative energy balance, it would be appreciated if you could provide some additional detail in the text related to the methodology of your laboratory experiments. (specific questions below)

Line 5, page 3: Exactly how was the top surface of your snow surface "contaminated with dust"? (i.e. sprinkling by hand, blowing, sieving, etc.?) Was this technique based on any previous study that could be cited?

Line 4-6, page 11: In these four idealized cases, how was the dust added in a $1 \mathrm{~mm}$ thick layer and how was it measured (case b) and how was it spread over the top 21 $\mathrm{mm}$ (case d)?

2) Previous micro-CT work on snow has often used a $0.5^{\circ}-0.7^{\circ}$ step size, a $180^{\circ}$ rotation, and a 10-17 um resolution, thereby reducing the overall scan time of a similarly sized sample to 20-30 min (see Heggli et al 2009, Chen \& Baker 2010, Wang \& Baker 2013, Hammonds et al 2015, Weise \& Schneebeli 2017, and others). In the work pre- 
sented here, a finer temporal and spatial resolution was used ( $3 \mathrm{~h}$ scan increment, 7.5 um resolution, $360^{\circ}$ rotation), but a $\sim 2 \mathrm{~h}$ scan time. . Can you please comment on the necessity of this increased resolution compared to previous work and the use of a $360^{\circ}$ rotation? Can you also comment about the potential for the inadvertent heating of the sample with such a long scan time? And whether or not an in situ temperature measurement was made in these experiments or others with such a long scanning period? Lastly, if this is the most spatially and temporally resolved micro-CT analysis of dry snow that has been performed (Line 29, page 3), which it appears to be, can you remark on the degree to which this study benefited from this increased resolution, compared to the established body of previous literature?

3) Regarding the three main types of dust movement, can you further explain your observation of Type 1 "creep of the ice matrix" (Line 7, page 7, Line 2, page 8, Line 10, page 9, Line 7, page 12)? More specifically, are you referring to the plastic deformation of individual ice grains and/or the ice matrix, or what some may consider "settling" within the test volume due to the gravitational force? If the latter, it is suggested that you change the text to reflect this, so as to not be confused with plastic deformation via creep (time dependent, low stress deformation). If the former, please provide additional detail as to how this deformation was measured and what kind of stress/load was causing this deformation.

4) Can you further elaborate on why "smaller particles are slightly faster than the larger ones"? (Line 12, page 9). Figure A.3 is not particularly convincing. Was this quantified over the entire size distribution of particles? Furthermore, what was the size distribution of the Mongolian Sand that was used?

5) Although the attention to detail demonstrated in this study is appreciated, it appears that repeating these experiments at least once could have provided a more robust set of conclusions with perhaps some margin of error that could then be included for the benefit of other researchers in the cryospheric sciences. . .can you please comment on why only one experiment of each temperature regime was conducted? And whether or

Printer-friendly version

Discussion paper
Interactive comment 
not you recommend further laboratory testing?

References:

Chen, S., and I. Baker (2010), Evolution of individual snowflakes during metamorphism, Journal of Geophysical Research: Atmospheres, 115(D21).

Hammonds, K., R. Lieb-Lappen, I. Baker, and X. Wang (2015), Investigating the thermophysical properties of the ice-snow interface under a controlled temperature gradient, Cold Regions Science and Technology, 120, 157-167, doi:10.1016/j.coldregions.2015.09.006.

Heggli, M., E. Frei, and M. Schneebeli (2009), Snow replica method for threedimensional X-ray microtomographic imaging, Journal of Glaciology, 55(192), 631-639.

Wang, X., and I. Baker (2013), Observation of the microstructural evolution of snow under uniaxial compression using X-ray computed microtomography, Journal of Geophysical Research: Atmospheres, 118(22), 12,371-312,382, doi:10.1002/2013jd020352.

Wiese, M., and M. Schneebeli (2017), Snowbreeder 5: a Micro-CT device for measuring the snow-microstructure evolution under the simultaneous influence of a temperature gradient and compaction, Journal of Glaciology, 63(238), 355-360.

Interactive comment on The Cryosphere Discuss., https://doi.org/10.5194/tc-2019-41, 2019. 